\title{
Black (Gifted) Joy: A Critical Race Theory Perspective
}

Word Count: 7224

Submission Date: February 4, 2021

\author{
Angela M. Novak, Ph.D. \\ Assistant Professor and Academically and Intellectually Gifted (AIG) Coordinator \\ Department of Elementary and Middle Grades Education, College of Education \\ East Carolina University \\ Speight 311, Mailstop 504, Greenville NC 27858 \\ 252-328-6649,novaka17@ecu.edu
}

\begin{abstract}
Author Biography
Angela Novak, Ph.D., is an Assistant Professor and AIG Coordinator at East Carolina University. She teaches undergraduate and graduate courses in education, focusing on assessment practices and gifted education. Dr. Novak has served NAGC and CEC-TAG in a variety of network, committee and board roles, and co-edited, with Christine Weber, a series of NAGC service publications related to professional learning. She has worked in public education in the gifted field as a classroom teacher, resource teacher, and central office support, as well as in the private not-for-profit sector of gifted education. She is an equity advocate, and is a member of the Diversity Scholars Network, from the National Center for Institutional Diversity (NCID) and is currently the Co-Chair of the Diversity and Equity Committee for NAGC.
\end{abstract}




\begin{abstract}
This article presents a theoretical question: what is giftedness, but an expression of Black joy? This is presented with relevant real-world examples and \#BlackVoices through youth poetry. The framework of critical race theory is used as a lens, to situate the world in which Black joy is found. The author argues that this manifestation, situated within the structural racism ever present in the system of education, has the unfortunate impact of igniting educators' anti-blackness, resulting in the missingness (Gentry et al., 2019) of gifted Black students from gifted programs and services. The author delves into constructs of white supremacy, white rage, and antiblackness as the foundational concepts that contribute to this missingness, using research and more youth poetry to substantiate the claims. \#BlackVoices are featured throughout, as emic perspectives, giving voice, heart, soul, and joy to the research, the words on the page.
\end{abstract}




\section{Black (Gifted) Joy: A Critical Race Theory Perspective}

Dr. Kissmekia Corbett, a Black scientist from Orange County North Carolina made headlines as a leading figure in the creation of one of the vaccines to inoculate against the novel coronavirus, approved in 2020. In viewing news coverage, seeing photographs of her studying science as an undergraduate and graduate student, and watching footage of crews touring her lab with her as an active research scientist today, Dr. Corbett exudes happiness. Her excitement in her work, her pride in her accomplishments, being unapologetically and rapturously unapologetically her true self can all be seen as an example of Black joy (Cruz, 2017). And what is giftedness, but an expression of Black joy? In this essay, I share the concept of Black joy, and how giftedness is an exemplar of Black joy through real world examples (Allen et al., 2019; Dionne, 2016; Whiting, 2019). Moreover, I argue that it is this manifestation of giftedness through Black joy, situated within the structural racism ever present in our society, and within the system of education, that has the deleterious impact of igniting educators' antiblackness, resulting in the missingness (Gentry et al., 2019) of gifted Black students from appropriate gifted programs and services.

\section{Foundations: Framework and Background Knowledge}

Foundational to the understanding of Black joy is a comprehension of the system of racism and oppression to which this joy is a resistance. I present this essay through the lens of critical theories of race, as a method of both understanding and transformational change.

\section{Positionality and Terminology}

Throughout this essay, I discuss ethnicity and equity and the nature of the topics bear identifying my positionality as a facet of the framework. I identify as a cisgender white woman and I acknowledge the privilege that comes with the intersection of my whiteness and gender 
identity, while also recognizing that it can be a tool for resistance as a co-conspirator (Love, 2019). My primary area of expertise is in gifted and talented education, and I further identify as an anti-racist educator (Kendi, 2019), an abolitionist teacher (Love, 2019), and I use equity literacy (Gorski \& Swalwell, 2015) as a transformational tool in my work. I position myself as an equity advocate and co-conspirator, acknowledging that I am on a path of understanding and knowledge; while I am not at the start, I am surely not at the end, nor will I ever be. I am intentional about engaging in ongoing learning experiences and seeking out feedback to continually learn and grow. Due to my positionality, an etic (outsider) viewpoint, throughout this essay I purposefully include Black voices as frequently as possible as exemplars with emic (insider) perspectives: researchers, activists, children.

This essay is specific to Black joy; some concepts may overlap other marginalized groups in gifted education; however, due to the focus of the essay, examples and research of similar concepts in other cultural and ethnic groups are not presented. I use the term Black throughout the essay as a consistent term rather than African American or People of the Global Majority. In my experience as an educator and researcher, Black is more universally preferred. Dumas (2016) capitalizes Black when referencing Black individuals, people, and institutions, as well as when referring to culture, while using lowercase for terms such as blackness, antiblackness, whiteness, and white. As Dr. Dumas is a senior scholar in the field, I follow his lead in this regard; these same terms when used in quotations, however, are left as the authors intended.

\section{Critical Race Theory}

Critical race theory (CRT) is somewhat unusual in that it is not just a way of seeking understanding, but it "contains an activist dimension. It tries not only to understand our social situation but to change it, setting out not only to ascertain how society organizes itself along 
racial lines and hierarchies but to transform it for the better" (Delgado \& Stefancic, 2017, p. 8). Undergirding critical race theory is the social construction thesis- the understanding that race is itself a creation of social thought, not a biological construct. "Not objective, inherent, or fixed, they correspond to no biological or genetic reality; rather, races are categories that society invents, manipulates, or retires when convenient” (Delgado \& Stefancic, 2017, p. 9). In describing this essay as a critical perspective, aligning with tenets of critical theories of race, it is with the understanding of several of the basic tenets of CRT: that racism is the standard in our society, it is the normal way of doing business; and that the current system of white supremacy in the culture provides both mental and material purposes for the dominant (white) group (Delgado \& Stefancic, 2017; Sleeter, 2017). "The first feature, ordinariness, means that racism is difficult to address or cure because it is not acknowledged" (Delgado \& Stefancic, 2017, p. 8). The second tenet of critical race theory is interest convergence, in which racism advances the interests of the dominant group; also called material determinism, it disincentivizes a significant portion of the population to work against racism (Delgado \& Stefancic, 2017; Sleeter, 2017).

Critical theories of race began first in law and policy domains, gradually moving into education. In their explanation of the history of critical race theory in education, Ladson-Billings and Tate decry that "more pernicious and long lasting than the victimization of people of color is the construction of whiteness as the ultimate property" (2016, p. 22), describing the " property functions of whiteness,' which include: (1) rights of disposition; (2) rights to use and enjoyment; (3) reputation and status property; and (4) the absolute right to exclude." Rights of disposition refers to "when students are rewarded only for conformity to perceived 'white norms' or sanctioned for cultural practices (e.g., dress, speech patterns, unauthorized conceptions of knowledge), white property is being rendered alienable" (Ladson-Billings \& Tate, 2016, p. 22). 
Rights to use and enjoyment is the ability of whites to use the societal, economic, and cultural privileges associated with their whiteness, whether it is the smaller class sizes, or the well-kept, extensive school property, it is both "performative and pleasurable.... The difference between those who possess the right to use and enjoy what schools can offer and those who do not" (Ladson-Billings \& Tate, 2016, p. 22). Reputation and status property is the act of damaging one's reputation through an assault on their property; "in the case of race, to call a white person 'black' is to defame him or her. In the case of schooling, to identify a school or program as nonwhite in any way is to diminish its reputation or status" (Ladson-Billings \& Tate, 2016, p. 23). This effect is theoretically felt in redistricting school zones, magnet programs, or bilingual education programs. Finally, the absolute right to exclude is the white property right in schooling to prohibit blackness. From the initial full restriction of Black children to the right to schooling to separate but equal, the absolute right to exclude continues to this day in the form of school vouchers, magnet schools, charter schools, and zero tolerance policies igniting the school to prison pipeline. Ladson-Billings and Tate (2016) share that within schools, this is evidenced by "resegregation via tracking, the institution of "gifted" programs, honors programs, and advanced placement classes. So complete is this exclusion that black students often come to the university in the role of intruders - who have been granted special permission to be there" (p. 23). This de facto segregation has been plaguing gifted programs since the inception of gifted programming.

Aligning CRT to education, Sleeter writes, "A core premise of CRT is that racism is endemic, institutional, and systemic; racism is not an aberration but rather a fundamental way of organizing society" (2017, p. 157). She continues, "the continued production of teachers, large proportions of whom are not well equipped to teach racially, ethnically, and linguistically diverse students well, is not an aberration. Rather, it is a product of racist systems to meet White needs" 
(p. 157). Ladson-Billings and Tate (2016) discuss a central theme of CRT as naming one's own reality, or voice. This component "provides a way to communicate the experience and realities of the oppressed, a first step on the road to justice...the voice of people of color is required for a complete analysis of the educational system" (p. 21). Sleeter identifies this tenet as experiential knowledge, "as dominant ideologies and knowledge systems based on White worldviews deny or mask racism, CRT theorists assume that those who understand racism best are not its perpetrators but rather those who are routinely victimized by it" (2017, p. 162). CRT provides the lens through which scholars ask questions, conduct analyses and relay findings.

\section{Black Joy}

Joy: pleasure, happiness, or delight. Black joy: "the free expression that comes from recognizing the love that our ancestors have allowed us to embody in the face of oppression." Activist Kleaver Cruz documented Roberta Hood's words and photograph on Instagram through an ongoing photojournalism series, \#TheBlackJoyProject (Dionne, 2016, para 40). Other responses Cruz captured include "magic actualized" by Tiffany L. Jones (para. 17) and "freedom and the release of inhibitions" from Arielle Newton (para. 21). Cruz himself defines Black joy as an act of resistance, "If we're existing in a world that tells us we shouldn't be good enough, enjoying our lives in spite of that is an act of resistance" (para. 3). Based on \#TheBlackJoyProject, Black joy can be thematically described as the unencumbered joy brought about by being one's true self, embracing the fullness of the expression of one's self; after two years into the project and over one thousand personal responses documented, this is the most common answer that Kleaver Cruz received (2017).

Dr. Bettina Love defines Black joy as, "a celebration of taking back your identity as a person of color and signaling to the world that your darkness is what makes you strong and 
beautiful...[it] is finding your homeplace and creating homeplace for others" $(2019$, p. 120). The concept of homeplace, a safe haven for Black bodies and minds to escape the brutality of white supremacy, adds a richness to the context of Black joy. bell hooks described homeplace as a site of resistance in Yearning: Race, Gender, and Cultural Politics (1990). Homeplace is both concrete, a physical space created by women, delegated so by sexism, and abstract, a mental construct. bell hooks describes the corporeal domain of homespace as, "spaces of care and nurturance in the face of brutal harsh reality of racist oppression, of sexist domination" (p. 384). Homeplace is both creating and sustaining a welcoming home environment that is their own. Beyond the concrete space, the physical construction of the home, homeplace is much more. As a form of resistance, Black women construct homespaces in which the community welcomed into their spaces strives "to be subjects, not objects, where we could be affirmed in our minds and hearts despite poverty, hardship, and deprivation, where we could restore to ourselves the dignity denied us on the outside in the public world" (hooks, 1990, p. 384). Homeplace and Black joy resonate deeply in these words from bell hooks:

This task of making homeplace... was about the construction of a safe place where black people could affirm one another and by doing so heal many of the wounds inflicted by racist domination. We could not learn to love or respect ourselves in the culture of white supremacy, on the outside; it was there on the inside, in that "homeplace," most often created and kept by black women, that we had the opportunity to grow and develop, to nurture our spirits. This task of making a homeplace, of making home a community of resistance, has been shared by black women globally, especially black women in white supremacist societies. (hooks, 1990, p. 384). 
Building upon bell hooks' tradition of poetry as a medium of expression, and CRTs tenet of voice, throughout this paper, I will use poetry that shares the lived experiences of Black youth. I intentionally provide a brief connection to the literature, leaving the interpretation of the poetry open to the reader. When a prompt required students to use the first line of a famous poem, Oakland, CA student Julian Khalil Allen used Walt Whitman's line from Leaves of Grass and penned "Song for Myself", giving words to his Black joy, and how his music could have a touch of homeplace for himself, and another.

Box off

\section{Song For Myself}

with opening line from Walt Whitman's "Song of Myself"

by Julian Allen

I celebrate myself and sing myself,

letting my own words give me power

to lead myself, indeed.

Indeed, I want not to have the lack of funds to feed myself.

Walking on the walk to the side.

I witness a lost soul displaying signs of missing

the song I sing. His hair grey at twenty, skin

dry, shoes unfly, spirit cold without energy.

Seeing him on the other side of Telegraph

makes my song falter. I wish I could cross

the street--perform that music to him.

(Allen et al., 2019, p. 13) 
End box off

“Song For Myself” is in Allen et al., a book of poetry entitled Black Joy: An Anthology of Black Boy Poems. Several selections are shared throughout the next section, as well, as exemplars of not just Black joy, but giftedness as a manifestation of Black joy.

\section{Giftedness as Black Joy}

"Black joy is an opportunity to use one of the most radical tools we have as Black people: our imagination" (Cruz, 2017, para. 15). Scholars have studied giftedness, and disagreed on the definitions and conceptions of giftedness, for a century. Many definitions include creativity as either a characteristic of giftedness or a type of giftedness. Creativity is the most natural fit, perhaps, with Black joy, but it is not limited to being imaginative. Cruz further explains that in expressing Black joy, “we are creating space to imagine how else we can exist. We must imagine both the demise of a global system of oppression as well as what will exist in its stead" (2017, para. 15). Additionally, in his Scholar Identity Model, Dr. Gilman Whiting identifies elements of gifted Black students that echo the descriptions presented of Black joy. Six characteristics of scholar identity are self-efficacy, self-awareness, racial identity and pride, future orientation, being willing to make sacrifices, a strong need for achievement, and academic self-confidence (Whiting, 2009). Speaking to race pride, Whiting writes, "they want greater self-understanding as a racial being, but also are aware of the importance of adapting to their environment and being bicultural. ... They refuse to be inhibited by social injustices based on gender, socioeconomic status, and race or ethnicity" (2009, p. 56). Consider Black Joy Anthology student Charles Hall's poem, "Sound of Joy" and the elements of Black joy, and giftedness expressed. Box off.

Sound of Joy \{editors: spacing, punctuation and capitalization as appears in the original poem\} 
erasure poem from The Writer's Chronicle, February '19

by Charles Hall

Words embroidering

the figure

And giving voice

to the suppressed

narrative

one trigger bringing

to the forefront

Turmoil.

Colors.

Authority.

(Allen et al., 2019, p. 19)

End box off.

Black gifted learners may exhibit characteristics of giftedness that are more closely aligned with their cultural norms, such as creative storytelling, both written and verbal, an advanced sense of humor (e.g., puns and jokes), and a penchant for direct and honest communication. (Ford, et al., 2002; Stambaugh \& Ford, 2015). These oral tradition characteristics may be interpreted by teachers as misbehavior or inappropriate, if they're not aware that they're showcasing their giftedness. An affective nature is another norm, with emotionality of expression as a defining characteristic of giftedness. Emotionality, along with cultural norms or peer pressure impact Black students (Ford, et al., 2002; Stambaugh \& Ford, 2015), such as in the phenomenon of acting white, a form of racialized bullying (Grantham, 
2014). Teacher reactions can vary from bystander to upstander; as bystanders, the adult response is one of self-preservation, inaction, and lack of ability or personal culpability in responding to race issues. By contrast, "at the heart of upstanding is simply taking a stand and adopting proactive roles to address an injustice... [e.g.,] caused by the burden placed on gifted Black students accused of acting white" (Grantham, 2014, p. 184). The National Association for Gifted Children has a yearly award called the Jenkins Scholars, provided to gifted Black youth. A 2017 Jenkins recipient, and 2019 Youth Poet Laureate, Haviland N.G. Whiting, published a book of poems, And What Would You Say if You Could? Her poem, "A Girl's First Love" has the vivid imagery, storytelling, and emotionality of a truly gifted Black girl and a clear message of Black joy: knowing and loving one's self.

Box off

\section{A Girl's First Love}

by Haviland N.G. Whiting

When a woman loves herself,

She reorganizes the way the world works.

When she takes off her clothes

Before a shower and

Admires her thighs,

The way her skin glows,

All of her body hair.

When she runs a finger over her lips,

A hand over her hips,

When she paints her stretch marks on 
Like fissures in a grand mountain.

When she carves out her glass rib cage

And shatters it like expensive crystal

When she runs a hand through her hair

Or over her scalp,

When she feels the strength in her teeth

And her eyelashes capable

Of catching tears,

And when she loves herself

So completely

And so wholly,

A woman can redesign the solar system,

And call herself a star.

(Whiting, 2019, p. 22)

End box off.

Two additional cultural manifestations of giftedness in Black students may be movement or verve and communalism (Ford, et al., 2002; Stambaugh \& Ford, 2015). Verve is movement, it is the act of expression, activity, dance, or constant motion. Students are well suited to being actively engaged through experiential learning, moving throughout the class period, and not restricted to a set of parameters (if there isn't a reason to sit in that one desk for an hour...why do it?). Communalism is a preference over individualism; teams over solo, or merely the opportunity to be social during work. Companionship and/or collaboration is more likely to produce the exemplar (Ford, et al., 2002; Stambaugh \& Ford, 2015). Black Joy Anthology 
student Samuel Getachew writes of Oakland, but not the city he knows. His storytelling is rich and has elements of verve, and his Black joy is thunderous.

Box off \{editors: spacing, punctuation and capitalization as appears in the original poem

\section{Cirque de Chênes}

by Samuel Getachew

some days i don’t recognize my city anymore

the new dress-up oakland i can't afford

some days i become a circus attraction in my own home

become the diversity factor of a room and everything my oakland is or used

to be becomes display case

and $\mathrm{i}$ become relic

an artifact worth framing but not saving and some days i have to force myself

to break the glass they trapped us in

exhibit A:

i enter a coffee shop i grew up going to and a chorus of pale mouths gape

so i laugh

all my teeth sharp and showing, whiter than their audience

and this performance becomes defiance,

and defiance becomes first fridays

becomes dancing through the gunshots, becomes a performance despite, becomes protest, and protest becomes the cookout and the music and the laughter and the laughter and the laughter. 
the smell of frying fish drifts out from somewhere nearby and i convince myself that last night's food trucks are lingering here instead

The scent of defiance and korean fusion tacos and weed and gasoline and sweat and permanence

exhibit B:

the music at first fridays ends sooner now

an 8 o'clock noise ordinance choking the soul out of telegraph nights

a new art gallery sits on the corner

a new cafe weaseled itself across from the beauty supply

west oakland morphing into a hipster's dream

exhibit C:

today i watch as an old black man gets out of his car and bursts into song

half the block stares

Startled by such a bold show of presence

captivated by this spectacle

trapeze artist missed the net

lion escaped

this was not supposed to happen.

and with 13 pairs of eyes on him

he sings a fight song for our city

syncopates his footsteps with the heartbeat of these streets and i seem

to be the only one who can hear them both

and in the moment 
my oakland is revived

rises up from the grave around me

becomes alive again in an earth-shaking chorus of

WE

\section{ARE}

\section{STILL}

HERE.

(Allen et al., 2019, pp. 7-8)

End box off.

An excited young scientist shouts out the answers, talks excitedly about growing plants and the experiments he plans. A bright young mind talks about microbiology, wonders aloud about germs and infections. She reminds her classmates, loudly, about washing their hands before lunch. A gifted writer entertains their classmates with stories during breaks. Are they praised for their giftedness? Or are they shushed for being off topic and bossy?

\section{Stomping Out Black Joy}

"Are there any high [ability Black students]?”, a second-grade teacher asked this in Howard's (2018, p. 562, emphasis added) study, indicating how whiteness as property, in this case the ownership of ability, operates in school spaces. The school, through its identification procedures, established a norm in which academically gifted students were expected to be white, which influenced the sorting of students into school spaces. This established stereotypes, setting a tone of "racialized exclusion and privilege within the school where the well-representation of White students was not only demographically accepted, but the privileges associated with GT status were also normalized. As a result, racialized exclusion and privilege were taught in school 
spaces" (Howard, 2018, p. 562). As discussed earlier, racism is a global term, sometimes easier to articulate and discuss than the topics of white supremacy, white rage, and antiblackness. However, impact of racism on the manifestation of giftedness as Black joy is based in antiblackness, and one cannot discuss antiblackness in isolation as it does not exist without white supremacy and rage.

\section{White Supremacy}

Layla Saad begins her book Me and White Supremacy by self-identifying as an East African, Middle Eastern Black, Muslim woman who is a British citizen living in Qatar. She was raised with the belief that she was a citizen of the world, in a home in which her cultural identity was valued, her religious beliefs were instilled, in a loving and supportive home environment. Nevertheless, she experienced relentless reminders of her otherness: radio, television, advertisements, at school, all provided minor connections with white supremacy in her daily world (Saad, 2020). "White supremacy is a racist ideology that is based upon the belief that white people are superior in many ways to people of other races and that therefore, white people should be dominant over other races" (Saad, 2020, p. 12). A key aspect to the definition is ideology; the systemic nature of ideology indicates that it is not merely beliefs or attitudes, but that it influences policies, economics, institutions, and structures. Another key term is dominance. Kendi (2019) draws a similar analogy indicating that racism is less about people and more about power and policy. He says that many people believe that the issue is ignorance and hate, and to eradicate racism, the solution is kindness, empathy, education. If that happens, racist policies, in this belief, would end. Kendi argues, however, that the people who enact racist policies already know "right from wrong"; that they enact the racist policies out of power, selfinterest, and dominance. "This cause and effect--a racist power creates racist policies out of raw 
self-interest; the racist policies necessitate racist ideas to justify them--lingers over the life of racism” (Kendi, 2019, p. 42). White supremacy connects strongly to many aspects of critical theories of race, in particular the property functions of whiteness tenet, as that connects to the beliefs in supremacy and ownership. When the ideology of supremacy is threatened, it triggers a host of negative feelings.

\section{White Rage}

Dr. Carol Anderson describes coming to the term white rage over the course of years, through hearing the violence against Black bodies perpetrated by police officers justified as a response to "Black rage"; after Michael Brown surrendered and was consequently murdered, she determined that this was not a result of Black rage, but of white rage.

With so much attention focused on the flames, everyone had ignored the logs, the kindling. In some ways, it is easy to see why. White rage is not about visible violence, but rather it works its way through the courts, the legislatures, and a range of government bureaucracies. It wreaks havoc subtly, almost imperceptibly. ... The trigger for white rage, inevitably is black advancement. It is not the mere presence of black people that is the problem; rather, it is blackness with ambition, with drive, with purpose, with aspirations, and with demands for full and equal citizenship. It is blackness that refuses to accept subjugation, to give up. (Anderson, 2017, p. 3-4)

White rage is characterized by normalcy, similar to CRT's tenet of racism existing in its ordinariness. A key aspect of white rage, and how it connects to white supremacy is how it is situated within the structure of the government, schools, and communities. Kendi (2019) says that labeling racism as systemic racism or structural racism is redundant; by its very nature, racism is systemic, it is structural. Kendi's semantical argument holds truth, however, it is clear 
that white supremacy and white rage fall into the same redundancy traps- but because they are hidden in plain sight, woven into the tapestry of the very fabric of American daily life, their normalcy has camouflaged them into complacency.

White rage is rooted in antiblackness. ... identify white rage as an emotional response by white people that is triggered when...Black people engage in freedom of movement, voice, or expression, it can disrupt white people's sense of blackness as something to be despised. From this disruption, white people experience feelings of disgust (Matias, 2016) and react by lashing out against blackness. This reaction of white rage may be individual but is also legitimated, carried out, and reinforced by institutional structures. (Blaisdell, 2020, p. 70-71)

Blaisdell draws the connection to antiblackness, as white supremacy, white rage, and antiblackness are interconnected; three emotional responses on the part of white individuals, against Black individuals, mentally, materially, and/or physically, supported and legitimized by society. I see an argument that the words systemic and structural are needed, even in their redundancy, because for many people "racism" implies solitary incidents rather than a culturalwide phenomenon, and the semantical redundancy of systemic racism helps to solidify that point. Antiblackness \{Note to Editor, ross does not capitalize\}

Dumas and ross (2016) describe critical race theory as a critique of white supremacy within a theory of racism. Blackness, however, is a theory situated in an anti-Black world: Critical theorization of blackness confronts the specificity of anti-blackness, as a social construction, as an embodied lived experience of social suffering and resistance, and perhaps more importantly, as an antagonism, in which the Black is a despised thing- 
in-itself (but not person for herself or himself) in opposition to all that is pure, human(e), and White). (p. 416-417)

In the formulation of BlackCrit, an underlying principle is antiblackness itself; that antiblackness is "endemic to, and central to how all of us make sense of the social, economic, historic, and cultural dimensions of human life" (Dumas \& ross, 2016, p. 429), mirroring the ordinariness of racism tenet found in CRT. Moreover, the concept is embedded in Afro-pessimism, which "posits that Black people exist in the social imagination as (still) slave, a thing to be possessed as property, and therefore with little right to live for herself, to move and breath for himself" (Dumas \& ross, 2016, p. 429). This existence in the social imagination remains because there lacks a clear moment in history between "slavery and acknowledgement of Black citizenship and Human-ness" (Dumas, 2016, p.14); and there lacks "a clear disruption of the technologies of violence--that is, the institutional structures and social processes--that maintain Black subjugation" (p. 14), therefore, Afro-pessimism argues that Black individuals are incapable of asking for rights, whether civil or human. "This does not deny the long legacy of Black racial struggle, but it positions this struggle as an impossibility, because the Black is (still) imagined outside of the citizenship that allows claims for redress to be regarded as legitimate" (Dumas, 2016, p. 14-15). It is in this lack of imagined citizenship, this lack of humanization, that creates the justification that whites use for the surveillance, dog-whistling, and hyper-punishment that is the epistemology of antiblackness (Annamma, 2017). An antithesis, a resistance, to this is Black joy.

\section{Spirit-Murdering in Action}

Like white supremacy, white rage is ever present, hidden in the daily fabric of the American tapestry as it "carries an aura of respectability and has access to the courts, police, 
legislatures and governors, who cast its efforts as noble, though they are actually driven by the most ignoble motivations" (Anderson, 2014, para 2). This white rage gives way to antiblackness and is, as argued previously, structurally, systemically pervasive. So pervasive, that it is seen as, in "Memory", by Haviland N.G. Whiting, to be a burden on those who carry the supremacy, rage, and antiblackness.

Box off

\section{Memory}

by Haviland N.G. Whiting

A girl slings her monogrammed backpack over her shoulder, "I wish black people didn't have to make everything about race."

A pause,

"Yes," I reply,

"Me too."

(Whiting, 2019, p.1)

End box off.

The impact on Black students, according to Dr. Bettina Love, is spirit-murder. She says that racism "literally murders your spirit. Racism is traumatic because it is a loss of protection, safety, nurturance, and acceptance- all things children need to be educated. The White rage in our schools murders dark students' spirits. Physical survival is not enough" (2019, p. 38).

The impact on their education, on gifted identification, is extensive. Howard (2018) found the impact of both whiteness as property and space as curriculum to be factors in the gifted program's perpetuation of white supremacy and racism. CRT's whiteness as property tenet created and fostered the system of racialized tracking, disproportionately classifying "white 
students into the segregated GT program [that] perpetually separated students physically, socially, and academically. Disproportionate representation was justified through a discourse of high ability used to determine the definition and measures of giftedness that systematically advantage White students" (Howard, 2018, p. 561). Students internalize gifted status and the space in the school building becomes part of their internalized curriculum; this teaches them about racialized power, privilege, and exclusion within the educational landscape. "The overwhelming Whiteness of representation sent a strong implicit message about race, where social and academic privileges were primarily the property of White students. This message was not lost on students who keenly observed the unspoken messages of ability tracking" (Howard, 2018, p. 563). Beyond the personal impact of the gifted program, is the impact on the teachers, and on identification.

Low teacher referrals are a frequent explanation for disproportionality in gifted programs. It is important to note the impetus, the root cause of these lack of referrals and missingness of Black students in gifted programs and services: oppression, racism, bias, or by the terms used thus far, white supremacy, white rage, antiblackness (Joseph, 2020; Novak \& Jones, 2020). Blaisdell (2020) studied an elementary school at length to determine how racism manifested at the school, allowing meaning to emerge from the examples the school provided. In one instance, a white teacher expressed that she believed that a Black principal favored Black faculty by sharing cupcakes, even when it is pointed out that she shares with faculty of all races; later, the favoring existed because the principal smiled at people. In this example, white rage is sparked and antiblackness engaged because of a perceived threat of blackness of collegiality, "particularly of Black comradery and joy. She witnessed Black people getting along and having fun - they were smiling at each other — and responded with white rage, i.e., the emotional need to 
curtail blackness expressed as positive" (Blaisdell, 2020, p. 79). This antiblackness is also expressed towards students, such as when a white teacher shared with the principal her frustrations with two children who dropped off their bags in the classroom and then went to the cafeteria for breakfast. The teacher said they act like they are "kings of the roost", and that one of the students, a Black student, should be suspended for these actions.

In terms of white supremacy, the above teacher's comments can be read as engaging in institutional whiteness as property that denied Black students the right to use and enjoy the privileges of whiteness, such as the freedom to bend rules a bit. Her desire for suspension, however, is more accurately read as a deeper disdain for blackness. The teacher was not just troubled by the Black student bending a school rule. She was troubled because, in her view, he was enjoying his freedom - to her, he was acting like he was "king of the roost" - and that expression of freedom triggered her white rage. The discipline data revealed that Pride had a broader issue of giving Black students less freedom, not more. Despite this evidence, this teacher drew on the epistemology of antiblackness to not only try and further limit this boy's freedom but to also push him out of school space completely. (Blaisdell, 2020, p. 82)

While these are behavioral examples, the trend holds for teachers' reactions to Black students' exhibitions of giftedness.

For what is giftedness, but an expression of Black joy? If a Black gifted child's oral tradition manifests as humorous storytelling, shared through Black joy and the teacher draws on the epistemology of antiblackness and stomps out that black joy, refusing to acknowledge the giftedness, seeing instead inappropriate humor, insolence, a trouble maker. Instead of a referral to the gifted program, the Black gifted child gets a referral to the office. If a Black gifted child's 
verve, their movement, natural (cultural) proclivity to dance and engage with their body and express themselves and be authentically who they are sparks white rage and antiblackness, they will be running laps at recess to get the energy out, not encouraged to explore their giftedness and challenged through experiential learning (Novak \& Jones, 2020).

Cruz questions, "What will it take for us to fully and unapologetically be ourselves all day every day everywhere? What will it take to live in a world that makes room for our whole existence?" (2017, para. 18). How can we move towards the recognition of giftedness as an expression of Black Joy, and even then, welcome it?

\section{Conclusion: Moving Forward with Abolitionist Teaching and Black (Gifted) Joy}

In We Want to Do More Than Survive: Abolitionist Teaching and the Pursuit of

Educational Freedom, Dr. Bettina Love speaks of Black joy that

originates in resistance, joy that is discovered in making a way out of now, joy that is uncovered when you know how to love yourself and others, joy that comes from releasing pain, joy that is generated in music and art that puts words and/or images to your life's greatest challenges and pleasures and joy in teaching from a place of resistance, agitation, purpose, justice, love, and mattering. (2019, p. 15)

Dr. Carol Anderson, in the 2017 paperback issue of White Rage, added an addendum, after the Trump election, in recognition of the voices rising up, the disbelief, the marches, the movements, the action. "This is how we begin to diffuse the power of white rage...The future is one that invests in our children by making access to good schools the norm, not the exception, and certainly not dependent on zip code" (Anderson, 2017, p. 175). These scholars speak to moving forward, resisting, persisting, and like the lens of critical theories of race, seek not just understanding but transformational change and activism. Love (2019) says: 


\begin{abstract}
Abolitionist teaching is not a teaching approach: it is a way of life, a way of seeing the world, and a way of taking action against injustice. ...There is no one way to be an abolitionist teacher. Some teachers will create a homeplace for their students while teaching them with the highest expectations; some will protest in the streets; some will fight standardized testing; some will restore justice in their classrooms; some will create justice-centered curriculums and teaching approaches... and some will do a combination of all of these. ...Abolitionist teachers fight for children they will never meet or see, because they are visionaries. They fight for a world that has yet to be created and for children's dreams that have yet to be crushed by anti-Blackness. (p. 89-90)
\end{abstract}

Systemic, structural racism, more specifically, white supremacy, white rage, antiblackness are key components in the missingness of Black students from gifted services. As educators, we have the opportunity to engage in abolitionist teaching (Love, 2019) to recognize giftedness in Black students, recognize Black joy, and work to dismantle the institutional racism, oppression and bias that actively blocks students from gifted programming, extending de facto segregation into a new century. Dr. J. Luke Wood developed the Black Minds Pedagogy, grounded in antiracism and abolitionism, in which educators "proactively extol the brilliance, dignity, and morality of Black minds.... actively seek[ing] to abolish the ideologies, practices, and narratives that maintain the system of oppression" (2019, p. 66). Abolitionist teachers fight for Black gifted children to have appropriate educational services, differentiated instruction that meets their needs, challenges their minds, and helps them learn and grow towards their greatest potential. Black joy is an expression of giftedness. Black joy, Black minds, and Black lives matter. 


\section{References}

\{Editors: hooks \& ross choose to use lowercase letters for their names\}

Allen, J. K., Evans, D., Getachew, S., Hall, C., Hynson, E.I., Hubbard-Riley, N. (2019). Black joy: An anthology of Black boy poems. Nomadic Press.

Anderson, C. (2014, August 29). Ferguson isn't about black rage against cops. It's white rage against progress. Washington Post. Opinions. https://www.washingtonpost.com/opinions/ferguson-wasnt-black-rage-against-copsitwas-white-rage-against-progress/2014/08/29/3055e3f4-2d75-11e4-bb9b997ae96fad33 story.html

Anderson, C. (2017). White rage: The unspoken truth of our racial divide. Bloomsbury.

Annamma, S. (2017). The pedagogy of pathologization: Dis/abled girls of color in the Schoolprison nexus. Routledge.

Cruz, K. (2017). Black joy is resistance: Why we need a movement to balance Black triumph with trials. Black Youth Project. Featured. http://blackyouthproject.com/black-joyresistance-need-movement-balance-black-triumph-trials/

Delgado, R., \& Stefancic, J. (2017). Critical race theory: An introduction. New York University Press.

Dumas, M. J., \& ross, k. m. (2016). Be real Black for me: Imagining BlackCrit in education. Urban Education, 51(4), 415-442

Dionne, E. (2016, May 24). This brilliant activist is helping Black people find joy- one Instagram photo at a time. Revelist. Race. https://www.revelist.com/race/black-joy-project-kleaver$\underline{\text { cruz/2094 }}$ 
Dumas, M. J. (2016). Against the dark: Antiblackness in education policy and discourse. Theory Into Practice, 55(1), 11-19.

Ford, D.Y., Harris, J.J.III., Tyson, C.A., \& Frazier Trotman, M. (2002). Beyond deficit thinking; Providing access for gifted African American students. Roeper Review, 24(2), 52-58.

Gentry, M., Gray, A., Whiting, G.W., Maeda, Y., \& Pereira, N. (2019). System failure access denied: Urgent! Systemic change required: Gifted education in the United States: Law, access, equity, and missingness across the country by locale, title I school status, and race. Authors. https://www.education.purdue.edu/geri/new-publications/gifted-educationin-the-united-states/

Gorski, P. C., \& Swalwell, K. (2015). Equity literacy for all. Educational Leadership, 72(6), 3440.

Grantham, T.C. \& Biddle, W.H. (2014). From bystander to upstander teacher for gifted Black students accused of acting white. Gifted Child Today, 37(3), 176-187. DOI: $10.1177 / 1076217514530117$.

hooks, b. (1990). Homeplace: A site of resistance. In Yearning: Race, Gender and Cultural Politics, 41-49. South End Press.

Howard, J. (2018). The white kid can do whatever he wants: The racial socialization of a gifted education program. Educational Studies, 54(5), 553-568.

Joseph, N. M. (2020). Introduction. In Nicole M. Joseph (Ed.). Understanding the Intersections of Race, Gender, and Gifted Education: An Anthology by and about Talented Black Girls and Women in STEM, pp. xiii-xxiii. Information Age Publishing.

Kendi, I. X. (2019). How to be an antiracist. One World/Ballantine. 
Ladson-Billings, G., \& Tate IV, W.F. (2016). Toward a critical race theory of education. In A.D. Dixson, C.K. Rousseau Anderson, \& J.K. Donnor (Eds.). Critical Race Theory in Education: All God's Children Got a Song, pp. 11-31. Taylor \& Francis Group.

Love, B. L. (2019). We want to do more than survive: Abolitionist teaching and the pursuit of educational freedom. Beacon.

Matias, C. E. (2016). Feeling white: Whiteness, emotionality, and education. Sense.

Novak, A.M., \& Jones, K.D. (2020). Gatekeepers in gifted: A case study of the disproportionality of gifted Black youth in elementary programs. Journal of Cases in Educational Leadership. https://doi.org/10.1177/1555458920976736

Pulliam, T. (2020, December 17). Dr. Kizzmekia Corbett praised as key scientist behind COVID-19 vaccine. $A B C$ 7. COVID-19 vaccine. https://abc7news.com/black-scientist-dr$\underline{\text { kizzmekia-corbett-praised-covid-vaccine-kizzy- }}$ facui/8794247/\#: : :text=Kizzmekia $\% 20$ Corbett $\% 20$ praised $\% 20 \mathrm{as} \% 20 \mathrm{key} \% 20$ scientist $\% 2$ 0behind $\% 20$ COVID $\% 2$ D19\%20vaccine\&text=A\%20Black\%20woman $\% 20$ from $\% 20$ Ora nge,to $\% 20$ solve $\% 20$ this $\% 20$ global $\% 20$ Pandemic

Sleeter, C. (2017). Critical race theory and the whiteness of teacher education. Urban Education, $52(2), 155-169$.

Stambaugh, T., \& Ford, D.Y. (2015). Microaggressions, multiculturalism, and gifted individuals who are Black, Hispanic, or low income. Journal of Counseling \& Development, 93, 192201.

Whiting, G.W. (2009). The Scholar Identity Institute: Guiding Darnel and other Black males. Gifted Child Today, 32(4), 53-56, 63.

Whiting, H.N.G. (2019). And what would you say if you could? Third Man Books. 
Wood, J.L. (2019). Black minds matter: Realizing the brilliance, dignity, and morality of Black males in education. Montezuma Publishing. 